\title{
Erratum to: The Antidepressant Fluoxetine Mobilizes Vesicles to the Recycling Pool of Rat Hippocampal Synapses During High Activity
}

\author{
Jasmin Jung ${ }^{1}$ - Kristina Loy ${ }^{1}$ Eva-Maria Schilling ${ }^{1}$ - Mareike Röther ${ }^{1}$ - Jan M. Brauner ${ }^{1}$. \\ Tobias Huth $^{2}$ • Ursula Schlötzer-Schrehardt ${ }^{3}$ • Christian Alzheimer ${ }^{2}$. Johannes Kornhuber ${ }^{1}$ • \\ Oliver Welzel $^{1} \cdot$ Teja W. Groemer ${ }^{1}$
}

Published online: 13 March 2017

(C) Springer Science+Business Media New York 2017

Erratum to: Mol Neurobiol (2014) 49:916-930

DOI 10.1007/s12035-013-8569-5

The authors missed to include an important statement in Acknowledgment. With this, the correct and complete statements are hereby published.

\section{Acknowledgements}

We thank Andreas W. Henkel for fruitful discussions and Katrin Ebert and Elke Meyer for excellent technical assistance. We would also like to thank Peter Gmeiner and Alina Tabor for assistance with the spectrophotometer. This work was conducted in partial fulfillment of the requirements for obtaining the degree Dr. rer. biol. hum. at FriedrichAlexander-Universität Erlangen-Nürnberg.

The online version of the original article can be found at http://dx.doi. org/10.1007/s12035-013-8569-5

\footnotetext{
Teja W. Groemer

teja.groemer@uk-erlangen.de

1 Department of Psychiatry and Psychotherapy,

Friedrich-Alexander-University of Erlangen-Nuremberg,

Schwabachanlage 6, 91054 Erlangen, Germany

2 Institute of Physiology and Pathophysiology,

Friedrich-Alexander-University of Erlangen-Nuremberg,

Universitaetsstr 17, 91054 Erlangen, Germany

3 Department of Ophthalmology, Friedrich-Alexander-University of Erlangen-Nuremberg, Schwabachanlage 6,

91054 Erlangen, Germany
} 